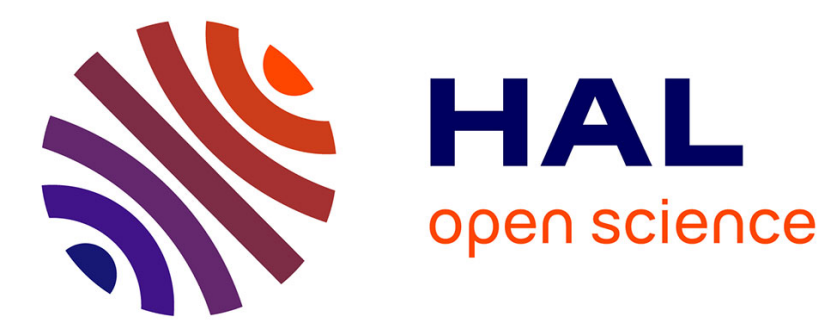

\title{
Crystallographic Study of an Adenovirus-Induced Protein Crystal in KB cells: a structural model
} Alain Lifchitz, Alexandre Rimsky, Gérard Torpier, Pierre Boulanger

\section{To cite this version:}

Alain Lifchitz, Alexandre Rimsky, Gérard Torpier, Pierre Boulanger. Crystallographic Study of an Adenovirus-Induced Protein Crystal in KB cells: a structural model. Acta Crystallographica Section B: Structural Science, Crystal Engineering and Materials [2014-..., 1975, 31, pp.441-445. 10.1107/S0567740875002981. hal-00015153

\section{HAL Id: hal-00015153 \\ https://hal.science/hal-00015153}

Submitted on 23 Feb 2006

HAL is a multi-disciplinary open access archive for the deposit and dissemination of scientific research documents, whether they are published or not. The documents may come from teaching and research institutions in France or abroad, or from public or private research centers.
L'archive ouverte pluridisciplinaire HAL, est destinée au dépôt et à la diffusion de documents scientifiques de niveau recherche, publiés ou non, émanant des établissements d'enseignement et de recherche français ou étrangers, des laboratoires publics ou privés. 
Acta Cryst. (1975). B31, 441

\title{
Crystallographic Study of an Adenovirus-Induced Protein Crystal in KB Cells: a Structural Model
}

\author{
By A. LifCHITZ AND A. RIMSKY \\ Laboratoire de Minéralogie et de Cristallographie associé au CNRS, Université de Paris VI, Tour 16, \\ 4 Place Jussieu, 75230 Paris Cedex 05, France \\ AND G. TORPIER AND P. A. Boulanger \\ Unité de Recherches $n^{\circ} 102$ de Virologie Moléculaire de l'INSERM, 2 Place de Verdun, 59045 Lille Cedex, France
}

(Received 19 June 1974; accepted 18 September 1974)

\begin{abstract}
The physical parameters of a protein crystal induced by adenovirus type 5 in KB cells were determined from images of positively contrasted, sectioned intranuclear crystals. Fourier transforms of digitized images showed that the net appearing on transverse sections of the crystals, thus far considered as hexagonal, was in fact pseudohexagonal, rectangular. The three-dimensional characteristics of the crystal unit cell were: $a_{o}=630, b_{o}=1200, c_{o}=900 \AA ; \alpha=\gamma=90, \beta=95 \cdot 5^{\circ}$. The space group was $P 2_{1}$. The asymmetric unit of the crystal was found to consist of a tubule centred by a densely stained tubular filament; its calculated molecular weight was $130 \times 10^{6}$ Daltons. A three-dimensional model was reconstructed from the crystallographic data.
\end{abstract}

\section{Introduction}

Intranuclear proteinic crystalline inclusions have been observed in cells infected with adenovirus type 5 (Leuchtenberger \& Boyer, 1957; Morgan, Godman, Rose, Howe \& Huang, 1957; Morgan, Godman, Breitenfeld \& Rose, 1960) and type 2 (Weber \& Stich, 1969; Henry, Stifkin, Merkow \& Pardo, 1971; Henry \& Atchison, 1971). In previous studies we have described the electron microscopic and biochemical characteristics of these crystalline bodies (Torpier \& Petitprez, 1968; Boulanger, Torpier \& Biserte, 1970): they consist of parallel tubules arranged on a crystalline lattice. From the ultrastructural data and from the results of biochemical and immunological studies on infected KB cell extracts and of immunofiuorescent staining (Torpier \& Boulanger, 1971) we have proposed a hypothetical model for this crystal (Boulanger, Torpier \& Biserte, 1970), assuming that it consists mainly of adenovirus capsid material, viz. hexon, penton and fibre capsomers, synthesized in considerable excess by the infected cell (Schlesinger, 1969). This hypothesis was first supported by Henry et al. (1971), then disproved by other workers, on the basis of immunofluorescent staining of crystal with an anti-adenovirus core hyperimmune serum, suggesting that crystals were related to adenovirus internal arginine-rich protein(s) (Henry \& Atchison, 1971; Marusyk, Norrby \& Marusyk, 1972).

It is the aim of the present study to present some additional information on the structure of adenovirus type 5 induced protein crystals in KB cell nuclei, with the aid of crystallographic data obtained from electron micrographs of longitudinally and transversely sec- tioned crystals (DeRosier \& Klug, 1968; Crowther, Amos, Finch, DeRosier \& Klug, 1970; Lake, 1972). Such a crystallographic analysis of adenovirion crystals in $\mathrm{KB}$ cell nuclei has recently permitted the determination of the mode of arrangement and association of the virions within the crystal packings (Boulanger, Torpier \& Rimsky, 1974).

\section{Materials and methods}

KB cells were grown as monolayers in 1 litre bottles $\left(3 \times 10^{7}\right.$ to $4 \times 10^{7}$ cells per bottle) in Eagle's basal medium supplemented with $10 \%$ calf serum. The cells were infected with adenovirus type 5 at a multiplicity of 100 infecting cell units per cell (ICU, Warocquier, Ménard \& Samaille, 1966), and harvested at $40 \mathrm{hr}$ postinfection. The cell pellet was fixed in $2.5 \%$ glutaraldehyde in $0 \cdot 1 M$ cacodylate buffer, $p \mathrm{H} 7 \cdot 2$, then post-fixed with osmium tetroxide and embedded in Araldite. Sections were stained in uranyl acetate + lead hydroxide.

Electron micrographs of transverse and longitudinal sections of adenovirus-induced protein crystals were densitometered, using a CALIFE automatic scanning microdensitometer in the Laboratoire Central de l'Armement (Arcueil). Computations were carried out at the Centre Interdisciplinaire Régional de Calcul Electronique (Orsay) on an IBM 370-165 computer with a $2100 \mathrm{~K}$ bytes core memory, using programs written in Fortran IV.

The Fourier transforms were performed on the digitized electron microscopic plates, by the Fast Fourier Transform algorithm (Cooley \& Tukey, 1965; Lifchitz, 1974), and the displays of these Fourier transforms were obtained with 20 intensity levels 
symbolized by the printing of 20 combinations of alphabetical and numerical characters (Epelboin \& Lifchitz, 1974).

\section{Results}

As observed on many electron micrographs, transverse sections through adenovirus-induced protein crystals reveal an approximately hexagonal lattice, limited by a polygonal convex contour, which shows that we are dealing with a real crystal [Fig. 1(a)]. Fig. 2 presents the digitized image of a transverse section observed at higher magnification, as shown in Fig. 1(b). The display of the Fourier transform (two-dimensional reciprocal space) performed by the Fast Fourier Transform algorithm on this digitized electron microscopic image presents a pseudohexagonal symmetry for the lowfrequency harmonics. This symmetry disappears for the higher frequency harmonics. Along a principal direction, designated as $\mathbf{b}^{*}$, a systematic extinction occurs for odd harmonics, whereas such an extinction does not exist along the direction $\mathbf{a}^{*}$, perpendicular to b* (Fig. 3). This implies a glide-reflexion line with translation of one half the repeat distance along the line $\mathbf{b}_{0}$ (Fig. 2). Hence the net is rectangular with a twodimensional space group $p g$ (No. 4), with two asymmetric units per unit cell and with the following parameters obtained from measurements made directly on a series of original micrograph plates: $a_{0}=630 \pm 30, b_{0}=$ $1200 \pm 60 \AA, \gamma=90^{\circ}$. The distances between the centres of the asymmetric units are respectively: $l_{1}=650 \pm 30$; $l_{2}=610 \pm 30 ; l_{3}=680 \pm 30 \AA$. Although different, the $l_{2}$ and $l_{3}$ values are of the same order and the coordinate of the asymmetric unit centres is therefore approximately $\frac{1}{4}$. The sectioned crystal habit is $01,11,1 \bar{T}, 0 \bar{T}$, $\overline{11}$ and $\overline{11}$.

Longitudinal sections [Fig. 4(a)] show that the crystal habit is polygonal convex with an elongation axis parallel to the crystal fibres. As for the transverse sections, the existence of such a polygonal convex contour implies a two-dimensional periodicity, a characteristic of the periodical media, and therefore suggests a periodical modulation along the fibre axis. Because the image seen on longitudinal sections corresponds to the planar projection of a roughly cylindrical fibre, the signal-to-noise ratio is low and the periodical modulation is scarcely visible. Nevertheless, if the longitudinal section micrographs are examined with a tangential incidence, the signal-to-noise ratio can be improved by physiological averaging of images on the retina, and this modulation appears clearly with an approximate wavelength of $10^{3} \AA$. The Fourier transform of the digitized image of the longitudinal section confirms this period, giving the value $c_{0}=$ $930 \pm 60 \AA$.

On the section presented in Fig. 4(a), one single fibre can be traced for its full length (up to $10 \mu \mathrm{m}$ ), proving that a net of fibres is totally contained in this section plane, for a section thickness of about $750 \AA$. The interfibre distance is $d=630 \AA$, which corresponds to the $l_{1}$ distance (Fig. 2). The interfacial angles $\left(\gamma_{1}=125\right.$, $\gamma_{2}=145, \gamma_{3}=140, \gamma_{4}=120^{\circ}$ ) allow the calculation of the axial ratio of the net, giving the respective values for the crystal parameters: $l_{1}=630 \pm 30, c_{0}=900 \pm 60 \AA$, $\beta=95 \pm 0 \cdot 5^{\circ}$ [Fig. $\left.4(b)\right]$.

The three-dimensional characteristics of the crystal unit cell are therefore as follows: $a_{0}=630 \pm 30, b_{0}=$ $1200 \pm 60, c_{0}=900 \pm 60 \AA ; \alpha=90, \beta=95 \pm 0 \cdot 5, \gamma=90^{\circ}$. The crystal belongs to class 2 of the monoclinic system. The space group is $P 2_{1}$, with two asymmetric units per unit cell.

From these crystallographic data, a value of $600 \times$ $10^{6} \AA^{3}$ can be calculated for the volume of the unit cell, hence $300 \times 10^{6} \AA^{3}$ per asymmetric unit. Assuming a mean value of $2.37 \AA^{3}$ for the volume of 1 Dalton of protein (Matthews, 1968), a molecular weight of $130 \times$ $10^{6}$ Daltons is obtained for the asymmetric unit. Assuming a density of 1.17 for crystal protein(s), as determined for adenovirus hexon crystals (Cornick, Sigler \& Ginsberg, 1973), one calculates a water content of $64 \%(\mathrm{w} / \mathrm{w})$ in the adenovirus-induced crystal.

\section{Discussion}

In spite of many studies, the nature of the adenovirusinduced protein crystals in infected cells remained conjectural. Recent immunological evidence (Henry \& Atchison, 1971; Marusyk, Norrby \& Marusyk, 1972) indicates that the crystals contain antigenic deter-

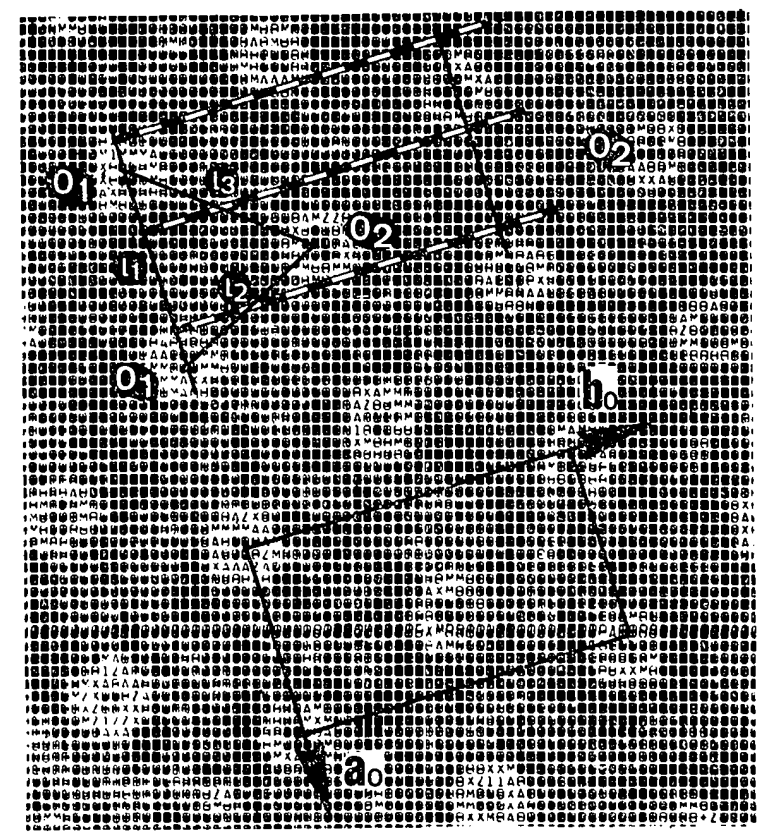

Fig. 2. Line printer direct display of a portion of the digitized negative electron microscopic plate showing the unit cell and the glide-reflexion line. $O_{1}$ and $O_{2}$ represent the centres of the two motifs contained in the unit cell, $l_{1}, l_{2}$ and $l_{3}$ the intercentre distances. The respective values given in the text for $l_{1}, l_{2}$ and $l_{3}$ correspond to an average of at least 20 measurements. 


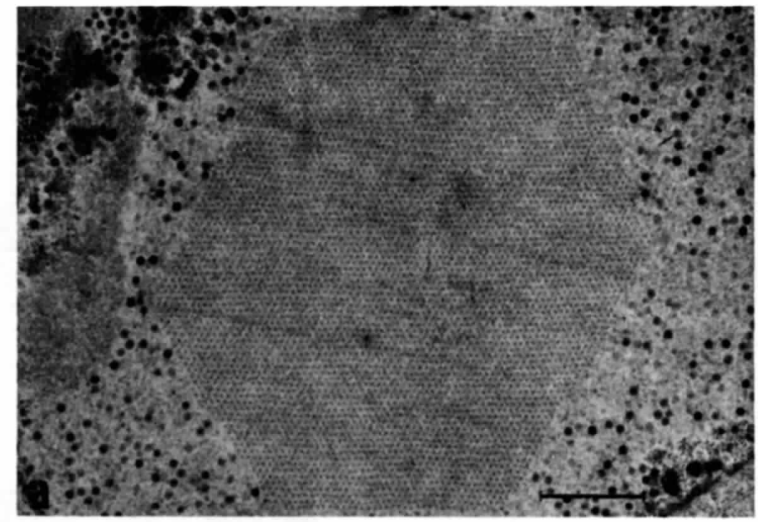

(a)

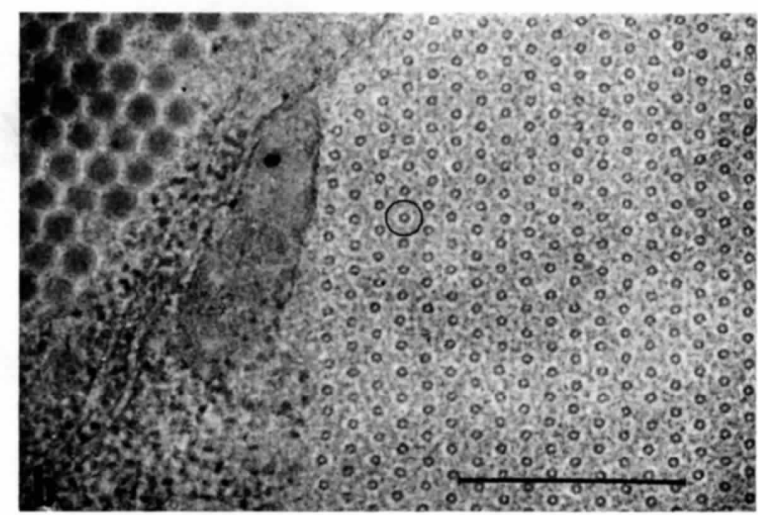

(b)

Fig. 1. (a) Electron micrograph of a transverse section of an adenovirus type 5 induced protein crystal in KB cell nucleus. The crystalline lattice is limited by a convex contour. The bar represents $1 \mu \mathrm{m}$. (b) A portion of transversely sectioned crystal at higher magnification. At the top left, a crystal of adenovirus particles neighbours the protein crystal. The limits of the asymmetric unit are clearly distinguishable along the edge of the crystal. This unit is formed of a faintly-stained tubule, polygonal in shape on section, centred by a densely-stained tubular fibre. The circle delineates an asymmetric unit. The bar represents $0.5 \mu \mathrm{m}$. 
minants of adenovirus arginine-rich internal core. However, the failure to find the expected large quantities of arginine-rich proteins in the crystal, either by biochemical analysis of a cellular subfraction containing the crystal components (Boulanger, Torpier \& Biserte, 1970; Torpier \& Boulanger, 1971), or by a polyacrylamide-gel electrophoresis study of the basic proteins isolated from adenovirus type-5 infected cells (Russel, 1971), led us to admit that the structure of this crystal is more complex than previously postulated. In addition, it seems hazardous to assess the exact nature and structure of the crystal from immunofluorescent staining, inasmuch as some antigenic determinants of crystal components can be masked within the crystalline matrix.

Nothing is known about the mechanism of formation of the crystals within the cell nucleus, but a geometrical pathway has been recently proposed (Wachman \& Levitzki, 1972) for the assembly of spherical viruses, involving a cubic crystal of capsomers as an intermediate, which collapses to form virus particles. If the collapse of the crystal structure does not occur

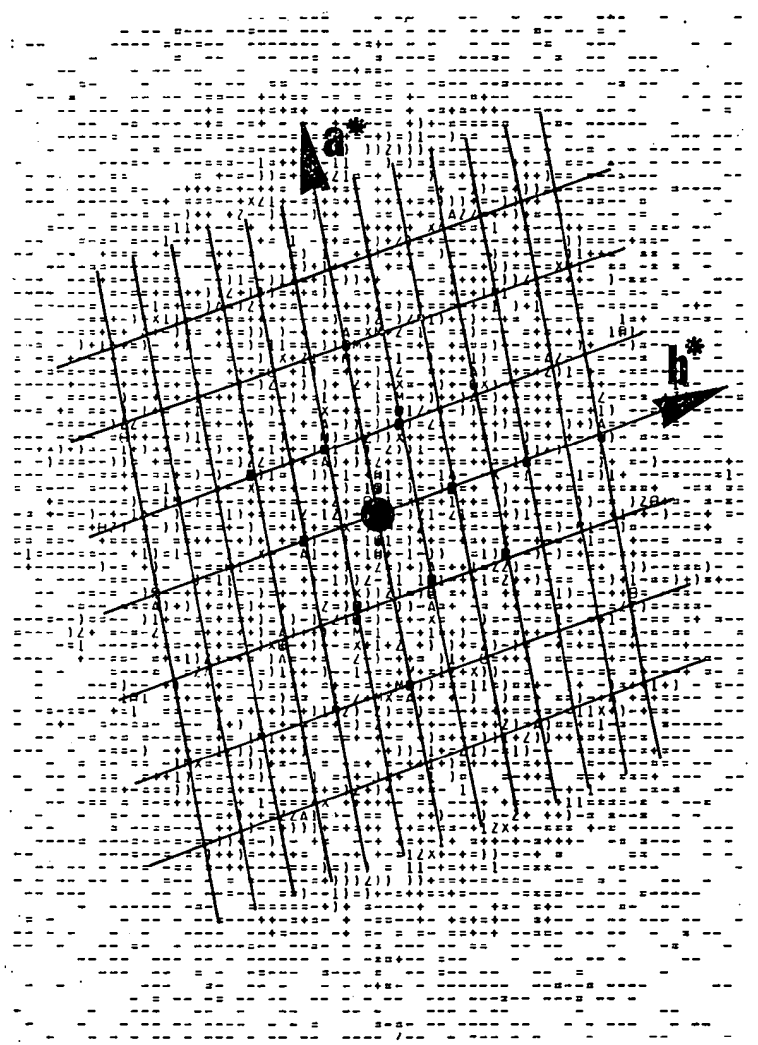

Fig. 3. Discrete Fourier transform corresponding to Figs. 1(b) and 2. Although a pseudohexagonal lattice is revealed by the intense diffraction spots, the true lattice appears rectangular, as materialized by the lines. A systematic extinction occurs for odd harmonics along the $b^{*}$ axis. The vertical affinity, due to the line printer display, has been intentionally corrected on Fig. 2, but not on Fig. 3 to prevent a loss of information. (As in Fig. 2, the code is given by Epelboin \& Lifchitz, 1974.) around a nucleation centre, such as the DNA-containing inner core of the adenovirus, but rather around a linear core, the collapse of the crystalline array is longitudinal and filamentary structures will result. Such filaments have been observed in KB cells infected with adenovirus type 5 (Torpier \& Petitprez, 1968, Plate III), in the process of generating crystalline inclusions within the nucleus. Other spherical animal viruses such as polyoma (Mattern \& De Leva, 1968) and herpes (Stackpole \& Mizell, 1968) also induce tubular inclusions in the host cell.

The adenovirus-induced crystal presents a tubular architecture: it consists of a crystalline array of faintly contrasted parallel tubules, polygonal in shape on transverse sections [Fig. 1(b)], centred by a densely stained tubular filament which seems connected to the peripheral tubule by a thin reticulum. The limits of the external tubular unit, and hence the limits of the asymmetric unit, are clearly distinguishable along the edges of the crystal [Fig. $1(a, b)$ ] as well as on isolated tubules in the course of assembling to form a crystalline array (Torpier \& Petitprez, 1968, Plate III).

If it is supposed that the adenovirus-induced protein crystal in the KB cell consists of viral capsid components, and particularly of hexon capsomers, the major adenovirus morphological subunits, collapsing around a filamentary axis of inner densely stained protein(s) (the formerly called 'tubules' of the crystal) to form longitudinal tubular fibres associating in a crystalline array, then it would be feasible to reconstruct from capsid components a three-dimensional structure compatible with the crystallographic data previously obtained. This is shown in Fig. 5(a): a plane hexagonal surface lattice of adenovirus icosahedron faces (equilateral triangles of $350 \AA$ edge), constituted of $12 \frac{3}{6}$ hexon capsomers, can be folded round upon itself to form a helical polyhedral tubule with an external diameter of $550 \AA$ and an axial periodicity of $930 \AA$. A unique structure possibility is thus found [Fig. $5(a, b)$ ], giving a tubular unit containing 28 triangles. In this hexagonal arrangement there is no room for pentons. From the most accurately determined molecular weight for hexon capsomer (298000, Cornick et al., 1973) a value of $104 \times 10^{6}$ is obtained for the molecular weight of this tubular unit. As the volume of the internal densely-stained tubular fibre is $56 \times 10^{6} \AA^{3}$, a molecular weight of $24 \times 10^{6}$ is calculated as mentioned above. The molecular weight of $128 \times 10^{6}$ for the whole tubular unit is in good agreement with the value of $130 \times 10^{6}$ inferred from crystallographic data.

The adenovirus-induced crystal would thus be formed of a crystalline array of helical polyhedral tubules $550 \AA$ in diameter, whose tubular unit consists of 28 triangular facets of $12 \frac{3}{6}$ subunits with hexagonal symmetry and molecular weight about 300000 , helicoidally disposed with a $930 \AA$ period. These hollow tubules contain a dense tubular fibre of basic protein(s). On the hypothesis that these hexagonal subunits are true adenovirus hexon capsomers, the occurrence of such 


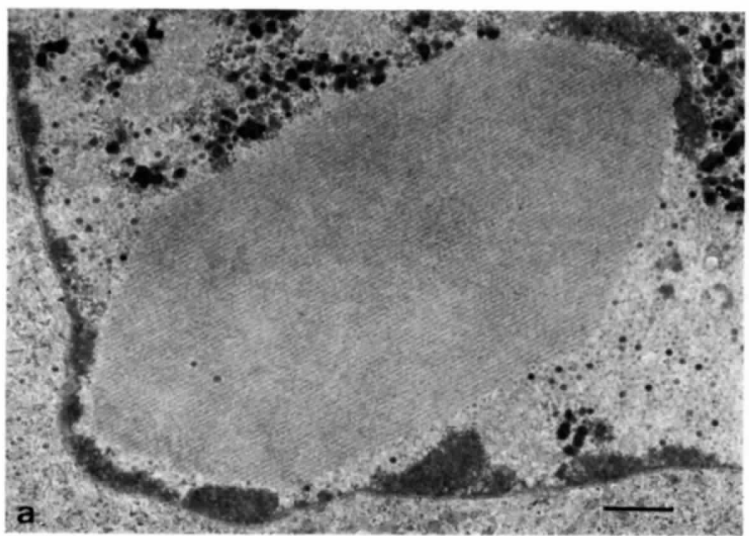

(a)

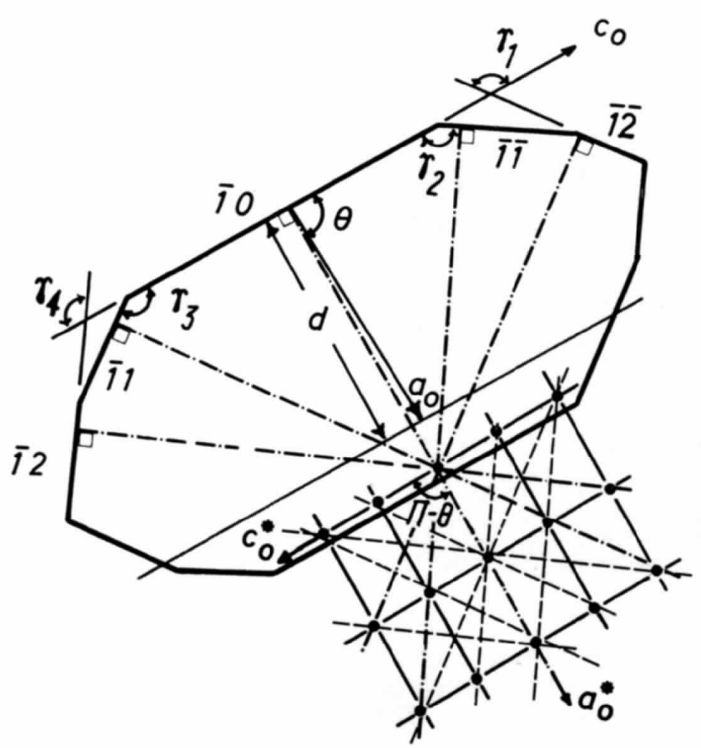

(b)

Fig. 4. (a) Electron micrograph of a longitudinal section of an adenovirus-induced protein crystal in the KB cell nucleus. The limits of the external tubular unit are visible at the periphery of the sectioned crystal. The bar represents $1 \mu \mathrm{m}$. (b) Determination of the crystal parameters by the crystal morphology. The reciprocal lattice is constructed from the directions perpendicular to the crystal faces. This reciprocal lattice permits the calculation of the direct parameters by the following equations: $\operatorname{tg} \theta=2 \sin \gamma_{2} \cdot \sin \gamma_{3} / \sin \left(\gamma_{2}-\gamma_{3}\right)$; $a_{0}=d / \sin \theta, d$ being the interfibre distance; $c_{0}=d$. $\sin \left(\gamma_{2}+\right.$ $\left.\gamma_{3}\right) / \sin \gamma_{2} \cdot \sin \gamma_{3}$.

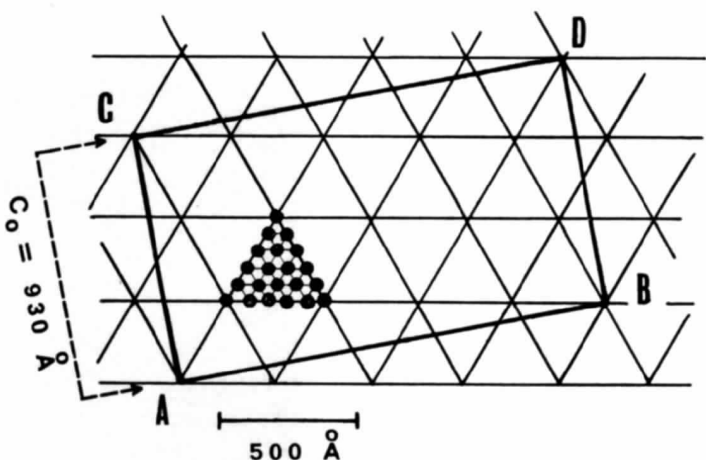

(a)

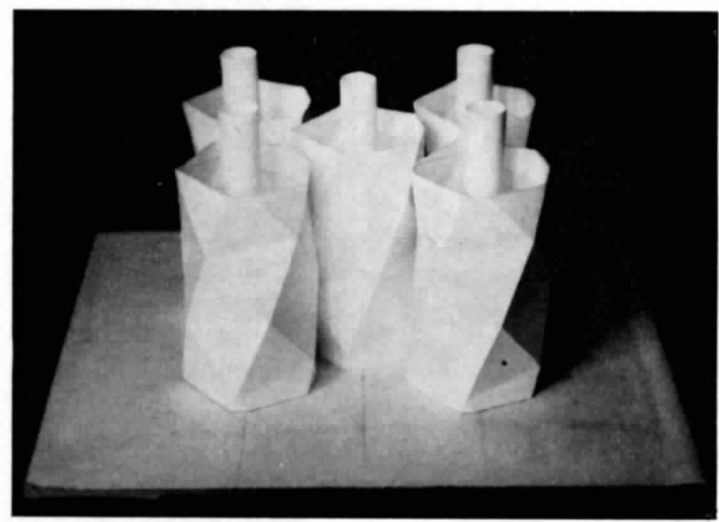

(b)

Fig. 5. (a) Plane hexagonal net of triangular facets (350 $\AA$ in edge; $12 \frac{3}{6}$ hexagonal subunits per facet) foldable round upon itself to form a helical polyhedral tubule, $550 \AA$ in diameter, $930 \AA$ in axial periodicity, $A C$ coming on $\mathrm{BD}$. (b) A proposed three-dimensional model for tubular units of adenovirus-induced crystal, reconstructed from crystallographic data. Each tubule is formed by helical enwinding of triangular plane facets of $12 \frac{3}{6}$ hexagonal subunits $(28$ triangles per asymmetric unit). The inner hollow fibre represents the densely-stained central filament of basic proteins. 
protein crystals in the KB cell would depend upon the synthesis rate of hexon and inner proteins and their excess over the other capsid components.

The proposed model [Fig. 5(b)], reconstructed from crystallographic parameters, is supported by a number of structural and biochemical arguments. (i) As calculated above, the parameters of the asymmetric unit of the unit cell are compatible with the dimensions of adenovirus capsid subunits. (ii) The phenomenon of epitaxy between non-viral crystals and virion crystals, visible in our electron micrographs [Fig. 1(b)], as well as in many others [Henry et al. (1971) Fig. 3(a); Marusik et al. (1972) Fig. $\mathrm{l}(A)$ ] strongly suggests some structural identity of the components of both crystals. (iii) The fine structure of the crystal has been shown to be related to the serotype of the inducing adenovirus, hence to the structure of the virus capsid components (Weber \& Liao, 1969). (iv) The relative resistance of the crystal to proteolytic enzymes (Martinez-Palomo \& Granboulan, 1967; Weber \& Stich, 1969) is reminiscent of the resistance of hexon to proteases (Valentine \& Pereira, 1965; Boulanger, Flamencourt \& Biserte, 1969; Pereira \& Laver, 1970). (v) The chromicity of the tubule wall in the sectioned crystal is the same as that of sectioned capsids in the intranuclear virion crystal. In contrast, the inner axial tubular fibre displays the same affinity for staining agents as does the inner core of adenovirons present in neighbouring area of the same cross section [Fig. 1(b)]. This inner core contains DNA-associated basic protein(s) (Prage, Petterson \& Philipson, 1968; Boulanger, Jaume, Flamencourt \& Biserte, 1970; Laver, 1970). (vi) The faint but positive immunofluorescent staining of the crystal with both anti-hexon and anti-adenovirion immune sera (Boulanger et al., 1970; Torpier \& Boulanger, 1971; Henry et al., 1971) implies the presence of capsid components within the crystal lattice. If confirmed, the model herein proposed for adenovirus-induced protein crystals would have the merit of explaining the apparently conflicting results of immunofluorescent staining with anti-hexon, anti-adenovirion and anti-virus core immune sera.

After completion of this study, we were informed of two works on adenovirus-induced protein crystals. In the first (Wills, Russel \& Williams, 1973), crystals were observed at $38.5^{\circ} \mathrm{C}$ in cells infected with Ad5-ts 17, an adenovirus type 5 temperature-sensitive mutant defective in hexon capsomer at this restrictive temperature. However, in that study, only achieved hexon antigen was explored by serological methods, and it was therefore possible that hexon synthesized at $38.5^{\circ} \mathrm{C}$ in the host cell was no longer antigenic, although still capable of forming crystals. At the nonpermissive temperature of $42^{\circ}$, we have also observed an absence of achieved hexon antigen, whereas hexon polypeptide unit is present (Warocquier \& Boulanger, 1973).

The second study was concerned with the isolation of a 'crystal' protein from Ad5-infected KB cells by
Marusyk and coworkers (Marusyk, personal communication): a protein of molecular weight 27000 has thus been obtained. The position of this protein could be the densely-stained tubular filament of the crystal unit.

This work was supported in part by contract CRL 74-5-043-03 from the Institut National de la Santé et de la Recherche Médicale, and by ERA 225 from the Centre National de la Recherche Scientifique. We thank Dr J. Berthou for his constructive criticisms and Dr W. Brown for his critical reading of the manuscript. The assistance of A. Petitprez in the Laboratoire de Microscopie Electronique de l'Institut Pasteur de Lille is gratefully acknowledged.

\section{References}

Boulanger, P. A., Flamencourt, P. \& Biserte, G. (1969). Europ. J. Biochem. 10, 116-131.

Boulanger, P. A., Jaume, F., Flamencourt, P. \& BiSERTE, G. (1970). J. Virol. 5, 109-113.

Boulanger, P. A., Torpier, G. \& Biserte, G. (1970). J. Gen. Virol. 6, 329-333.

Boulanger, P. A., Torpier, G. \& Rimsky, A. (1974). Intervirology, 2, 56-62.

Cooley, J. W. \& Tukey, J. W. (1965). Math. Comput. 19, 297-301.

Cornick, G., Sigler, P. B. \& Ginsberg, H. S. (1973). J. Mol. Biol. 73, 533-538.

Crowther, R. A., Amos, L. A., Finch, J. T., DeRosier, D. J. \& Klug, A. (1970). Nature, Lond. 226, 421-425.

DeRosier, D. J. \& Klug, A. (1968). Nature, Lond. 217, 130-134.

Epelboin, Y. \& Lifchitz, A. (1974). J. Appl. Cryst. 7, 377-382.

Henry, C. J. \& Atchison, R. W. (1971). J. Virol. 8, 842849.

Henry, C. J., Slifkin, M., Merkow, L. P. \& Pardo, M. (1971). Virology, 44, 215-218.

LAKe, J. A. (1972). J. Mol. Biol. 66, 255-269.

LAVER, W. G. (1970). Virology, 41, 488-500.

Leuchtenberger, C. \& Boyer, G. S. (1957). J. Biophys. Biochem. Cytol. 3, 323-324.

LifChitz, A. (1974). Acta Cryst. A 30, 86-92.

Martinez-Palomo, A. \& Granboulan, N. (1967). J. Virol. 1, 1010-1018.

Marusyk, R., Norrby, E. \& Marusyk, H. (1972). J. Gen. Virol. 14, 261-270.

Mattern, C. F. T. \& De Leva, A. M. (1968). Virology, 36, 683-685.

Matthews, B. W. (1968). J. Mol. Biol. 33, 491-497.

Morgan, C., Godman, G. C., Rose, H. M., Howe, C. \& HuANG, J. S. (1957). J. Biophys. Biochem. Cytol. 3, 505516.

Morgan, C., Godman, G. L., Breitenfeld, P. M. \& Rose, H. M. (1960). J. Exp. Med. 112, 373-382.

Pereira, H. G. \& Laver, W. G. (1970). J. Gen. Virol. 9, 163-167.

Prage, L., Petterson, U. \& Philipson, L. (1968). Virology, 36, 508-511.

Russel, W. C. (1971). J. Gen. Virol. 11, 65-69.

Schlesinger, R. W. (1969), Advanc. Virus. Res. 14, 1-61. 
Stackpole, C. W. \& Mizell, M. (1968). Virology, 36, 63-72.

Torpier, G. \& Boulanger, P. A. (1971). Ann. Inst. Pasteur Lille, 22, 269-282.

Torpier, G. \& Petitprez, A. (1968). J. Microsc. 7, 411-418. Valentine, R. C. \& Pereira, H. G. (1965). J. Mol. Biol. $13,13-20$.

Wachman, A. \& Levitzki, A. (1972). J. Theor. Biol. 34, 277-287.
Warocquier, R. \& Boulanger, P. A. (1973). Arch. Ges. Virusforsch. 41, 371-381.

Warocquier, R., Ménard, D. \& Samaille, J. (1966). Ann. Inst. Pasteur Lille, 17, 97-106.

Weber, J. \& LiaO, S. K. (1969). Canad. J. Microbiol. 15, $841-845$.

Weber, J. \& STich, H. F. (1969). J. Virol. 3, 198-204.

Wills, E. J., Russel, W. C. \& Williams, J. F. (1973). J. Gen. Virol. 20, 407-412. 